\title{
Playing with Creativity Across the Lifespan: a Conversation with Dr. Sandra Russ
}

\author{
Shagun Singha ${ }^{1} \cdot$ Melissa Warr ${ }^{1} \cdot$ Punya Mishra ${ }^{1} \cdot$ Danah Henriksen ${ }^{1} \cdot$ The Deep-Play Research Group
}

Published online: 27 May 2020

(C) Association for Educational Communications \& Technology 2020

"Play is a creative product."

- Dr. Sandra Russ

"A little magic can take you a long way"

- Roald Dahl

In this article, we continue with our series exploring creativity and its relationship with technology and learning. As part of the series, we have interviewed scholars who approach creativity from psychological (Richardson et al. 2018), social (Keenan-Lechel et al. 2019), humanist (Mehta et al. 2019), neuro-biological (Mehta et al. 2017), as well as a range of other disciplinary perspectives and lenses. We have also spoken with researchers who study creativity as it presents in different domains and contexts: as writers (Cain et al. 2020), musicians (Warr et al. 2018), designers (Henriksen et al. 2017), dramatic artists (Richardson et al. 2019), and dancers (Warr et al. 2019). Through these conversations, we have attempted to create a rich and nuanced picture of the vibrancy of current creativity research. We seek to add to that picture here through an exploration of creativity and play.

Punya Mishra
punya.mishra@asu.edu
Shagun Singha
ssing257@asu.edu
Melissa Warr
mcwarr@asu.edu
Danah Henriksen
danah.henriksen@asu.edu
Arizona State University, Tempe, AZ, USA
Our most recent conversation was with Dr. Sandra Russ, a creativity and play expert, and interim dean of the College of Arts and Sciences and Professor of Psychology in the Department of Psychological Sciences at Case Western Reserve University. In this conversation, we explored her research on pretend play and creativity and the importance of nurturing play and creativity across the lifespan. We also examined the role of play and creativity during crisis situations such as the COVID-19 pandemic.

Dr. Russ is a distinguished scholar and an expert in the field of creativity and play. Her current role as interim dean involves furthering faculty scholarship, including providing faculty with a supportive research environment to explore their interests and inquiries through meaningful work. She carries the title of Distinguished University Professor as well as a Louis D. Beaumont University Professor and is a recipient of the Rudolf Arnheim Award for Outstanding Achievement in Psychology and the Arts.

Dr. Russ offers an interdisciplinary perspective on the study and measurement of affect and creativity. She is perhaps best known for her foundational measure, The Affect in Play Scale, that is used to measure imagination and emotional expression in pretend play (Russ et al. 2000). She is also the author of a number of books that discuss the role of affect and play in creativity (e.g., Russ 2003, 2014).

Trained as a clinical psychologist, Dr. Russ works primarily with children. It is no surprise, then, that a significant focus of her research centers on developing a better understanding of the role of pretend play in child development and psychotherapy. She approaches this work from a cognitive, affective, and developmental perspective which she refers to as psychodynamic-developmental (Russ 1993). She has explored the relationship between pretend play and areas of adaptive functioning such as creativity, coping, and emotional understanding (Russ 2003) and she is currently exploring the role of affect in the creative process. 


\section{Play as a Creative Product}

Dr. Russ described creativity as "the ability to come up with original ideas; to put ideas or images or experiences together in new ways" and "synthesizing in an original way using fantasy." This description is similar to existing definitions of creativity, particularly the emphasis on novelty - but it also contrasts with many characterizations of creativity which additionally include a type of usefulness or effectiveness criteria. The so-termed 'standard definition' of creativity espoused by creativity scholars (Runco and Jaeger 2012) implies a two-part definition of creativity: creativity requires both novelty (or originality) and usefulness (or effectiveness). In this series we have also spoken of Mishra et al.'s (2013) NEW definition of creativity, i.e. a creative product is novel, effective, and whole.

The standard definition accounts for creativity in valuedriven or outcome-bounded contexts, in which utility and collective value judgments of effectiveness matter significantly. For instance, a performance might be deemed creative if it has elements of novelty and if audiences or critics find it to be effective, enjoyable, cohesive, engaging, thought provoking, etc. (i.e. effective). Or, in the sciences, a new discovery could be creative if it offers new knowledge or an inventive scientific solution (i.e., something useful that works well). Runco (2012) raised the possibility of diverging from the standard definition and only considering originality, but novelty and effectiveness still reign supreme in definitions. But with the standard definition, what are we to do with more personal creativity which does not sit easily with an obvious 'effectiveness' judgment? Or, related to Dr. Russ's work, what of children's creativity which includes elements of imagination or novel thinking but does not fit on a typical scale of usability or effectiveness?

Dr. Russ, while sensitive to other definitions of creativity, believes that, for children, the criteria of usefulness cannot be the most important. This is because for children, play is the creative product. As she explained, play is "an output of how [children] think and how they feel." In other words, play as a creative product has intrapersonal value, i.e., it is inherently meaningful to the person doing the playing.

Viewing play as a creative product provides insight into the relationship between play, creativity, and emotion. Dr. Russ (2016) views pretend play as a vehicle for creative expression and an opportunity for a child to generate new ideas. This allows children to synthesize images or experiences together in whole and original ways. Children, she suggests, come up with and process new ideas through play and fantasy. Notably, Vygotsky $(1960,1978)$ focused on this element of creativity through imagination and fantasy as central to children's learning and development. He believed that creativity develops in three stages: creative imagination begins in childhood, then proceeds into adolescence, where imagination comes together with thought, and finally moves into adulthood, where experienced creativity is directed and used with purpose. He described children's figurative play as a catalyst for creative imagination. Thus, imagination and fantasy, which are sometimes dismissed as 'child's play,' are central to how people develop creatively throughout life.

Like creativity, play is often novel, surprising, and original. For example, Dr. Russ described how a child might transform objects like Legos into something else entirely. Children practice divergence in play. She explained how they might "generate different ideas, make up creative stories ... incorporate different images like going to the moon, and use fantasy."

Children are creative both in and through play, and significant empirical evidence supports a relationship between play and creativity (Lieberman 2014; Russ 2014). For example, Hoffmann and Russ (2012) found pretend play to be positively correlated with divergent thinking, storytelling, and emotional regulation. Russ et al. (1999) discovered that the relationship between play and divergent thinking holds across time - in their study, children's play ability scores predicted their divergent thinking scores four years later.

Clearly, play and creativity both include characteristics of divergent thinking, but how else might play and creativity be related? We argue that Dr. Russ's view of play as a creative product brings a new meta-level meaning to the "effectiveness" criteria common in other definitions of creativity.

Toward that argument, it may be important to ask "effective for whom?" Is it for broader society and culture, for smaller interpersonal contexts, or for the individual? The complexity of value judgments has been an ongoing conundrum in creativity literature, and it highlights the perspectival nature of creative outcomes and products (e.g. Who judges and why? And who judges the judges?) (Runco and Jaeger 2012). Beghetto and Kaufman (2007b) addressed this dilemma by describing a spectrum of creativity in their 4-C creativity model: Big-C, little-c, pro-c, and mini-c. Big-C creativity is landmark work. Its scope changes a field or the world - for example, the invention of cubism by Picasso and Braque, the development of the theory of relativity by Einstein, or the invention of the personal computer by Jobs, Gates, and others. Little-c creativity, in contrast, is smaller in scope but just as important in our lives. It describes "everyday creativity that may make a solid contribution" (p. 76). It might include a piece of art made for others or a new process that makes the workplace more efficient. Little-c creativity does not have the same scale as Big-C, but it has interpersonal value and is additive and cumulative in its effects on people and society. "Pro-c involves relevant types of experts' creativity or insights that are useful and critical in professional domains. The outputs of pro-c creativity may not change the field, but they still make a difference. For example, in education, this might be seen in the pioneering idea of the flipped classroom from Bergmann and Sams (2012). Finally, "mini-c" is "intrapersonal creativity that is part of the learning process" (p. 76). In other 
words, mini-c creativity holds value for the individual and is interpretative and often relevant in classrooms (e.g. a 2nd grader's insight about how to solve a math problem). Beghetto and Kaufman (2007a) described how "all levels of creative performance follow a trajectory that starts with novel and personally meaningful interpretations" (p. 59) and develops into interpersonal expressions. This broadened spectrum of creative scope suggests that labeling the criterion of effectiveness is highly subjective and situated. It reflects Stein's (1953) work distinguishing between the internal and external frames of reference that might be used when considering and judging creativity.

From this perspective, the creativity inherent in pretend play is highly effective: it supports children in working out ideas and expressing themselves. In other words, play is how children learn. As Maria Montessori famously said, "play is the work of the child." The process and product of play are inherently novel and effective. Pretend play is also an affective process that supports "both the ability to think about affect-laden fantasy and the capacity to experience emotion" (Russ 2003, pp. 292-293). Play, as a creative product, can effectively help children think, feel, and process information. From an evolutionary perspective, it supports learning that connects with and influences thinking. Play provides an effective foundation that is unparalleled by less joyful and more rote forms of learning (Pellegrini et al. 2007).

Although we have emphasized the differences between children's pretend play and adult creativity, mini-c creativity and play are not reserved for children alone. Adults also benefit from play and other forms of mini-c creativity; they can work through challenges and express emotions through mini-c creativity. This is where our conversation with Dr. Russ went next.

\section{Nurturing Creativity and Play for All Ages}

Play not only helps children (and adults) process challenges and emotions but also supports other (little-c and perhaps evenBig-C) forms of creativity. Dr. Russ believes that effective play in childhood leads to increased creativity in adults, but she also accepts that this can be hard to scientifically prove. Returning to Vygotsky's $(1960,1978)$ theoretical work, play is indeed developmental in certain ways that expand and extend across the lifespan. Given his assertion that children's figurative play catalyzes creative imagination, Vygotsky proposed that creativity was an intentionally acquired mental ability. People apply play and creative thinking to modify and combine ideas in context, generating unique, beautiful, and useful discoveries. As Dr. Russ notes, however, finding clear empirical evidence of the link between childhood play and adult creativity requires longitudinal studies, and identifying creativity in adults can be difficult because many adults have limited opportunities to express creativity. Nonetheless, she argues that play and creativity have clear mental health benefits and should be nurtured and encouraged across the lifespan - and this is certainly grounded in foundational educational psychology.

Young children simply need to play, and, for the most part, nurturing children's creativity can be as easy as ensuring they have the time and space to do so. In The Evolution of Childhood, Melvin Konner (2010) emphasized the value and necessity of play for learning, noting that among juveniles of any age group, play is a core activity. Yet there is also a great energy expenditure that comes from play, including increased food requirements and risk. The skill would not have evolved without significant adaptive value. Konner noted that you can watch children of any age engage in "rough and tumble play" and see that it is quite different from the aggressive action of real fighting - yet the play builds physical, developmental, and motor skills. Even beyond the important development of physical coordination and motor skills, play of all kinds helps humans and other species learn to account for and handle unexpected events, establish and practice social relationships, self-assess and consider risks, stimulate mental development, and practice imagination and creative adaptation.

Some children, however, struggle with play. In these cases, Dr. Russ notes that guided play can help them develop creative potential and imaginative skills. For example, she described Hoffmann's (Hoffman \& Russ 2016) research on play interventions. Hoffman worked with groups of 1 st and 2nd grade girls. Each group included two girls that scored low on pre-assessments of pretend play ability as well as two girls who scored higher. During the interventions, Hoffmann supported the students in making up imaginative stories. After six 30-min sessions, students who originally scored low on preassessments and participated in the intervention showed a significant increase in pretend play, positive affect, creativity, and divergent thinking compared to the control group.

Play becomes less frequent as children grow. That, however, does not mean that play loses significance. Dr. Russ argues that teenagers should also be encouraged to practice creative expression, particularly by following developing interests. Teenagers can participate in arts programs - drama, music, dance, visual arts - as well as practice creativity in academic subjects through activities such as science projects or creative writing. In terms of Beghetto and Kaufman's (2007b) creativity model, teenagers can be encouraged in both intrapersonal (mini-c) creativity and interpersonal expression (little-c creativity). Creativity provides teenagers opportunities to problem-solve and encourages growth across domains. This is even more important for underprivileged students who rely on schools to provide creative opportunities that they might not have access to at home.

When asked to summarize the implications of her scholarship for educational policy makers, Dr. Russ explained:

[Essentially] you have to find a way to look at the individual child throughout the whole 12 years that they're 
in an educational system and focus on nurturing the development of that child. So, keep the continuity there. .. [provide] as many creative activities as possible in those early years, give them the opportunity to explore music, dance, science so that they start to see what they enjoy and what they're good at, so that they can start to gravitate to areas that they really like and that they have talent in.

Adults, she argued, also need opportunities to be creative and play. Although many adults do not have opportunities for Big-C creativity in the workplace, they are still capable of participating in little-c and mini-c creativity. And, according to Dr. Russ, play and creative expression are important for the mental and emotional health of all ages - particularly during difficult situations, like the COVID-19 pandemic.

\section{Play and Creativity during a Pandemic}

We talked with Dr. Russ over video chat in late March 2020, just as countries in Asia, Europe, and North America were shutting down to control the spread of COVID-19. The recent changes in our work and lifestyle were at the forefront of our minds and we naturally gravitated to discussing the shifts we were seeing around us as school closed and more people worked from home. This context provided an opportunity to dig deeper into the essential elements of play and the role play has in the lives of both children and adults during crises. Much of our discussion centered on whether new technologies can support play and creativity, particularly when children must stay at home.

During the pandemic, children are limited in their ability to physically play with friends, but many have access to video games. Here, technology can potentially be a conduit for play when other circumstances are more limited. Dr. Russ believes video games can support play and creativity but emphasized that the central requirement for pretend play is for the play to be open-ended. Thus, games that are flexible and allow children to use their imaginations can support play and creativity. For example, Minecraft provides a platform for children (and adults) to create new worlds.

Dr. Russ also discussed the potential for conducting play interventions over video platforms. Dimitropoulos et al. (2017) reported on a telehealth play intervention for children with Prader-Willi syndrome, a rare developmental disorder similar to autism. In play sessions, interventionists supported children in creating stories about emotions and problems. Throughout the process, the interventionists modeled play behaviors. For example, Dr. Russ explained, "One child following a story needed to get milk for a baby but said that there's no milk bottle. And so, the researcher could just pick up a Lego and say, well, this could be a milk bottle. It's modeling that you can use an object to be something else." Even though the interventionist and child were in different physical locations with different toys, the interventionist could still support the child in working out problems in pretend play. This suggests that play is not limited or fully bound by physical spaces, and during times of crisis and isolation, the connectivity supported by digital technologies can afford creative play.

At the time of the interview, we were also observing some positive outcomes of the pandemic: adults stuck at home were spending more time with creative activities, and many children had more time to play. Dr. Russ described how parents had been observing children participating in pretend play with the virus. She was recently interviewed by The Atlantic (Cray 2020) where she explained that play of this nature was a natural way for children to process what was going on in their world. In fact, it could be argued that it is not just children who are processing trauma through play. Adults are also processing emotion through play and creativity, as evidenced by humorous songs, comedy shows produced via video conference, and arts-based benefit specials, all focusing on our shared experience with COVID19. As human beings, we are programmed to use play and creative expression to connect and work through difficulties. Creativity is not just about finding solutions to problems; it is about expressing emotion and processing change. Forgeard's (2013) work on creativity and mental health has shown that engaging in creative activities can provide people with noticeable improvements to their mental health and overall wellbeing. Indeed, many clinicians report that people receiving treatment for both mild and severe mental health issues experience significant therapeutic benefits and inspiration from creative hobbies and habits. While the medical community has begun to recognize the value of creativity for mental health through programs for arts-based activities such as visual arts, music, drama, dance, poetry, writing or other forms of creative play there is also an accessible value to these expressions, in that they can be engaged and indulged in our personal spaces and lives. This brings us again to the personal value of mini-c creativity and the ways in which play can move us and help us to expand, learn, heal, and grow over the lifespan.

\section{Conclusion}

Our conversation with Dr. Russ meandered through a range of topics about play, creative expression, emotion, and how we as humans cope with challenges. It highlighted how important play and creative expression are in difficult times, begging the question of how we can support children in developing the habits and abilities of play and creativity from childhood. Dr. Russ believes that it is simpler than we might think:

It's a matter of nurturing joy. So, what I say to parents is - enjoy them. Enjoy the play with your three, four, or five-year-old's. Play with them and enjoy the play. With 
older children, you may stay out of it, but make sure they have time and space and appropriate toys. There are so many ways you can nurture this and then it will take care of itself.

If there is one takeaway from our conversation with Dr. Russ, it is that play and creativity are effective tools for supporting mental and emotional health, something particularly critical during crises such as the COVID-19 pandemic. Play and creative expression can help us cope with an uncertain world, which is always the world we face looking ahead into the future.

\section{References}

Beghetto, R. A., \& Kaufman, J. C. (2007a). The genesis of creative greatness: mini-c and the expert performance approach. High Ability Studies, 18(1), 59-61. https://doi.org/10.1080/ 13598130701350668.

Beghetto, R. A., \& Kaufman, J. C. (2007b). Toward a broader conception of creativity: a case for "mini-c" creativity. Psychology of Aesthetics, Creativity, and the Arts, 1(2), 73-79.

Bergmann, J., \& Sams, A. (2012). Flip your classroom: Reach every student in every class every day. Eugene, Alexandria: International Society for Technology in Education.

Cain, W., Henriksen, D., Mishra, P., \& The Deep-Play Research Group. (2020). Words and worlds: a conversation on writing, craft, and the power of deep fandom with Kij Johnson. TechTrends. https://doi. org/10.1007/s11528-020-00495-3.

Cray, K. (2020). How the coronavirus Is influencing children's play. The Atlantic. Retrieved from Psychology of Aesthetics, Creativity, and the Arts, 6(2), 175. 0.1037/a0026299

Dimitropoulos, A., Zyga, O., \& Russ, S. (2017). Evaluating the feasibility of a play-based telehealth intervention program for children with Prader-Willi syndrome. Journal of Autism and Developmental Disorders, 47, 2814-2825. https://doi.org/10.1007/s10803-0173196-z.

Forgeard, M. J. (2013). Perceiving benefits after adversity: The relationship between self reported posttraumatic growth and creativity. Psychology of Aesthetics, Creativity, and the Arts, 7(3), 245.

Henriksen, D., Mishra, P., Warr, M., \& The Deep-Play Research Group. (2017). A cybernetic perspective on design and creativity: a conversation with Dr. Paul Pangaro. Tech Trends. https://doi.org/10.1007/ s11528-017-0232-y.

Hoffmann, J., \& Russ, S. (2012). Pretend play, creativity, and emotion regulation in children. 10.1007/s11528-019-00404-3

Hoffmann, J. D., \& Russ, S. (2016). Fostering pretend play skills and creativity in elementary school girls: A group play intervention. Psychology of Aesthetics, Creativity, and the Arts, 10(1), 114.

Keenan-Lechel, S. F., Henriksen, D., \& The Deep-Play Research Group. (2019). Creativity as perspective taking: an interview with Dr. Vlad Glăveanu. TechTrends, 63, 652-658. https://doi.org/10.1007/ s11528-019-00437-8.

Konner, M. (2010). The evolution of childhood: Relationships, emotion, mind. Harvard University Press.

Lieberman, N. J. (2014). Playfulness: Its relationship to imagination and creativity. New York: Academic Press.
Mehta, R., Henriksen, D., Mishra, P., \& The Deep Play Research Group. (2017). The courageous rationality of being a neuroskeptic neuroscientist: Dr. Arne Dietrich on creativity and education. TechTrends, 61(5), 415-419. https://doi.org/10.1007/s11528-017-0217-x.

Mehta, R., Henriksen, D., \& The Deep-Play Research Group. (2019). An Embodied, Dialogic Endeavor: Towards a posthumanizing approach to creativity with Dr. Kerry Chappell. TechTrends, 63, 612. https://doi.org/10.1007/s11528-018-0357-7.

Mishra, P., Henriksen, D., \& The Deep-Play Research Group. (2013). A NEW approach to defining and measuring creativity: rethinking technology \& creativity in the 21 st century. TechTrends, 57(5), 10.

Pellegrini, A. D., Dupuis, D., \& Smith, P. K. (2007). Play in evolution and development. Developmental Review, 27(2), 261-276.

Richardson, C., Henriksen, D., \& the Deep-Play Research Group. (2018). It's not 'hippies running barefoot through a field of daisies' and other contemplations on creativity with Dr. Jonathan Plucker. Tech Trends. https://doi.org/10.1007/s11528-018-0323-4.

Richardson, C., Henriksen, D. \& the Deep-Play Research Group (2019). Questioning the myth of ideation: Tatiana Chemi and the Hard Work of Creativity. TechTrends, 63: 245-250. https://doi.org/ 10.1007/s11528-019-00391-5

Runco, M. A. (2012). The new science of creativity. Taylor \& Francis.

Runco, M. A., \& Jaeger, G. J. (2012). The standard definition of creativity. Creativity Research Journal, 24(1), 92-96.

Russ, S. (1993). Affect and creativity: The role of affect and play in the creative process. Hillsdale: Lawrence Earlbaum Associates.

Russ, S. (2003). Play in child development and psychotherapy: Toward empirically supported practice. New York: Routledge.

Russ, S. (2014). Pretend play in childhood: Foundation of adult creativity. Washington, DC: American Psychological Association.

Russ, S. (2016). Pretend play: antecedent of adult creativity. New Directions for Child and Adolescent Development, 2016(151), 2132. https://doi.org/10.1002/cad.20154.

Russ, S., Robins, A. L., \& Christiano, B. A. (1999). Pretend play: longitudinal prediction of creativity and affect in fantasy in children. Creativity Research Journal, 12(2), 129-139. https://doi.org/10. 1207/s15326934crj1202 5.

Russ, S., Niec, L. N., \& Kaugars, A. S. (2000). Play assessment of affect: The affect in play scale. In K. Gitlin-Weiner, A. Sandgrund, \& C. Schaefer (Eds.), Play diagnosis and assessment. Retrieved from https://psycnet.apa.org/record/2001-01062-026

Stein, M. I. (1953). Creativity and culture. Journal of Psychology, 36, 31322.

Vygotsky, L. S. (1960). Imagination and its development in childhood. In L.V. (Ed.), The development of higher mental function (pp. 327362). Izdatel'stvo Academii Pedagogicheskikh Nauk RSFSR: Moscow.

Vygotsky, L. S. (1978). Mind in society: The development of higher psychological processes. Cambridge: Harvard University Press.

Warr, M., Henriksen, D., Mishra, P., \& The Deep-Play Research Group. (2018). Creativity and flow in surgery, music, and cooking: an interview with neuroscientist Charles Limb. TechTrends, 62(2), 137142. https://doi.org/10.1007/s11528-018-0251-3.

Warr, M., Henriksen, D., Mishra, P., \& The Deep-Play Research Group. (2019). Creativity and expressive arts, performance, physicality and wellness: A conversation with Dr. Paula Thomson and Dr. Victoria Jaque. TechTrends, 63(2), 102-107. https://doi.org/10.1007/ s11528-019-00372-8.

Publisher's Note Springer Nature remains neutral with regard to jurisdictional claims in published maps and institutional affiliations. 